\title{
Measurement of Temperature Fields in Long Span Concrete Bridges
}

\section{J. Římal}

This paper deals with assesing of the influence of climate temperatures on deformations and stresses in a cross section of the Nusle Bridge. The main purpose is to describe the measurement of the thermal fields, to compare measured and computed temperature fields, and to provide a real estimation of the stresses that occur.

Keywords: Nusle bridge in Prague, measurement of thermal fields, calculation of temperature fields, evaluation of stress fields.

\section{Introduction}

The endeavour to improve building technologies has the same importance as the tendency to reduce the mass of structures. This can be done in two main ways:

- by choosing statically efficient structural designs and building technologies,

- by using materials with high strength properties.

Modern computation methods enable the exploitation of hidden reserves of carrying capacity, i.e., designs that make full use of the strength of materials. At the same time, these methods lead to certain problems, which are seen in the decreasing durability and lifetime of structures. The main reasons for this lie in the action of the external environment chemical influences, temperature and moisture. Temperature and moisture create corresponding volume changes, followed by the inception of deformations and stresses.

The influence of temperature and moisture could be neglected in massive structures, but this is no longerthe case for modern buildings. The supplementary state of stress due to volume changes is usually a primary cause of microcracks, and forms the basis for the subsegment process of corrosion and degradation.

\section{Bridge structure}

Nusle Bridge, the largest prestressed concrete bridge in the Czech Republic, was built in 1973 (see Photo 1). The bridge structure with a full-span of $485 \mathrm{~m}$ is divided into five spans $68.25+3 \times 115.50+68.25 \mathrm{~m}$.

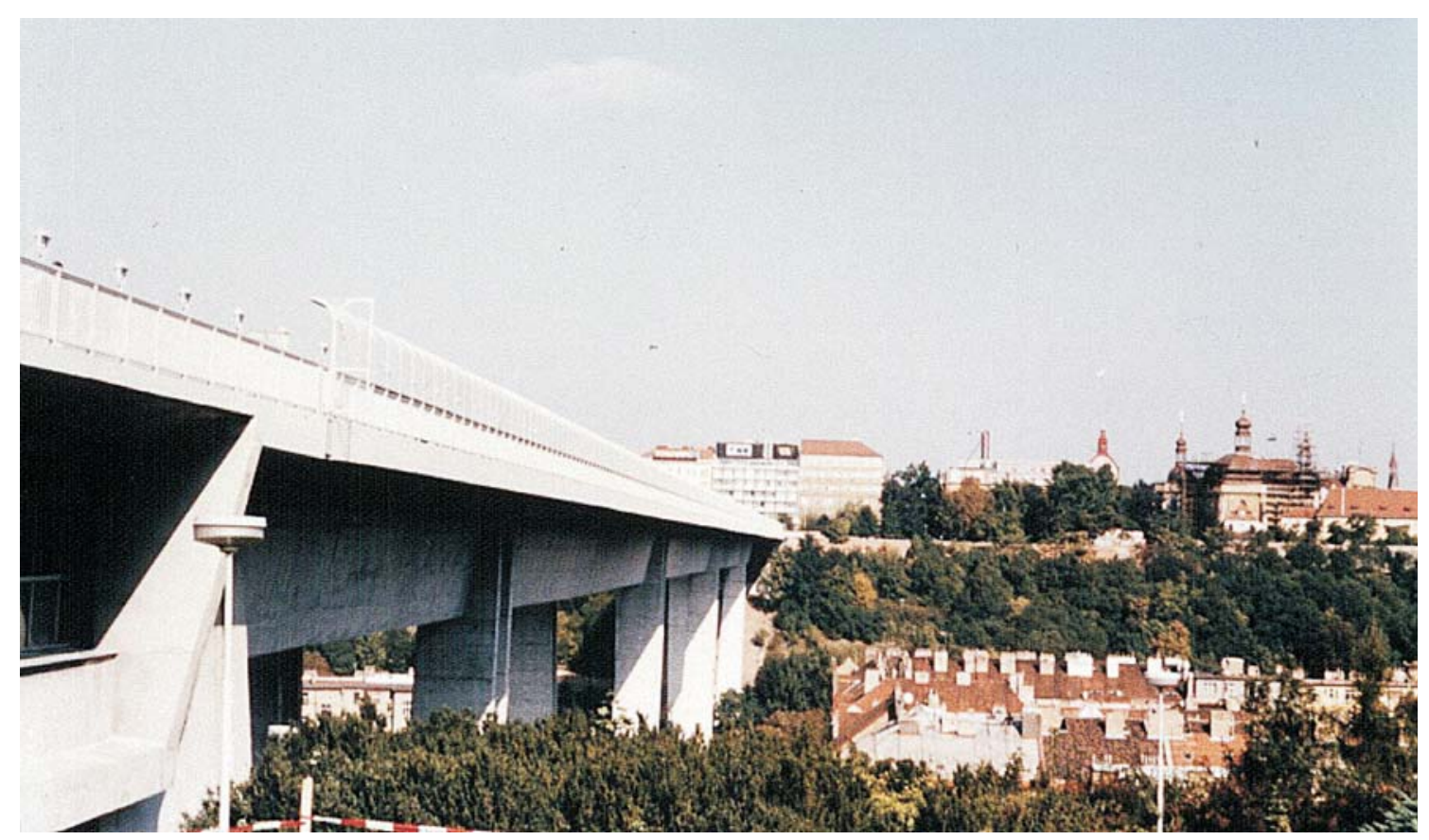



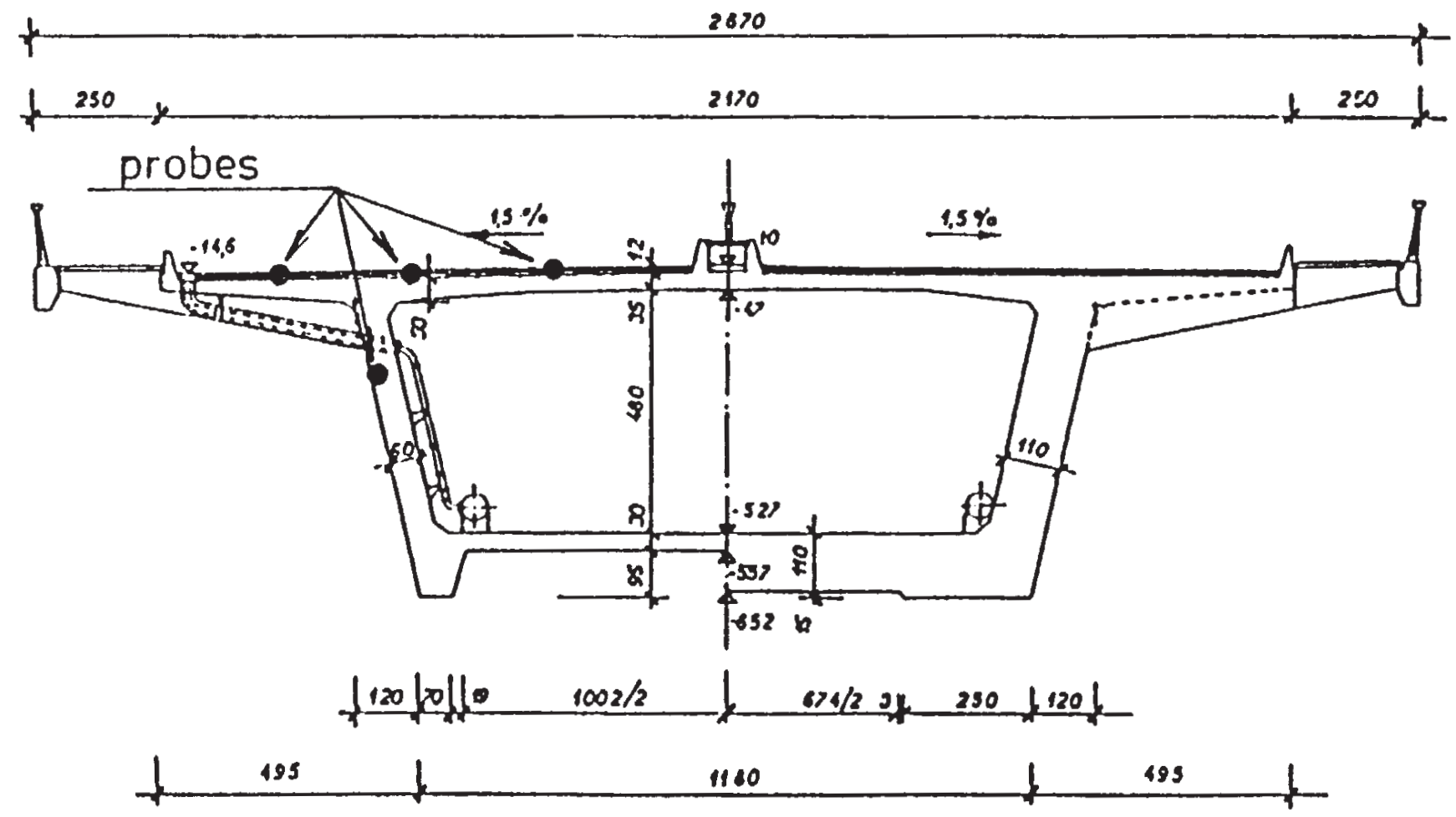

Fig. 1: Cross section of the bridge and location of thermal probes

The cross-section sizes are shown in Fig. 1. The bridge decking structure, at the time of measurement, is described in Tab. 1 and Fig. 2.

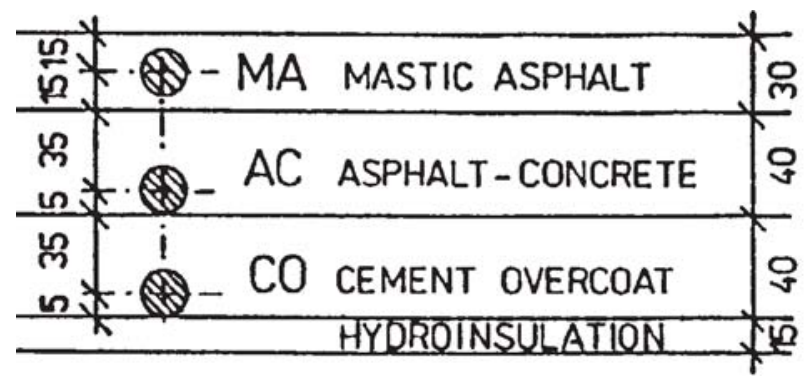

Fig. 2: Structure of the bridge decking and placing of the thermal probes in the cross section

Table 1: Construction of bridge decking

\begin{tabular}{|c|c|c|}
\hline MARKING & MATERIAL & THICKNESS [m] \\
\hline MA & mastic asphalt & 0.03 \\
\hline AC & asphalt-concrete & 0.04 \\
\hline CO & cement overcoat & 0.04 \\
\hline HI & hydroinsulation & 0.01 \\
\hline PC & prestressed concrete & \\
\hline
\end{tabular}

\section{Measurement of thermal fields in the bridge decking and bridge structure}

\section{a) Thermal probes}

The special thermal probes were developed on the basis of MT $100 \Omega$ platinum resistant thermometers. The probes conformed to the requirements of accuracy, reliability, durability, safety, waterproofness, and mechanical stress. Each sensor was calibrated in the laborarory. The calibration constants were determinated in relation to the control of the entire experiment by means of a personal computer.

b) Location of thermal probes; cable line to the measurement centre

The probes were placed approximately in the middle of each traffic line, see Fig. 1. The vertical location of the sensors is shown in Fig. 2. The grooves for the cable line and the holes for lateral placing of the sensors were made in the bridge decking. Other holes for placing the thermal sensors were made in the bridge structure. The cable lines led to the measurement centre, which was placed in the underground station located below one end of the bridge.

\section{c) Measurement centre}

The measuring sets are capable of telemetering the temperature at the measuring points with simultaneous reading of all measured values and objective recording of the values. 

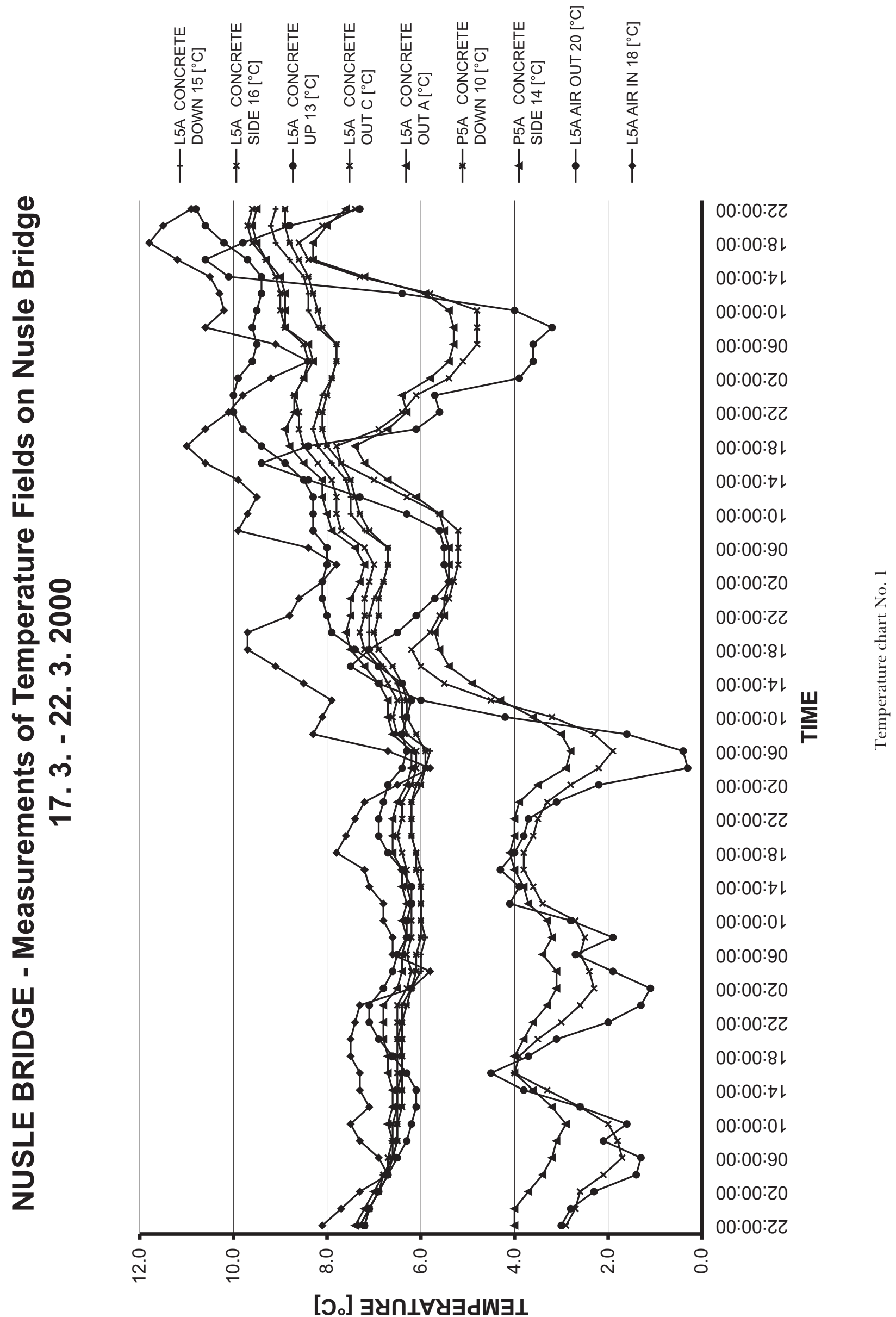
The measuring sets consist of:

- ULTRAKUST 5601-11ABE digital multimeter

- cascade controlled series of ULTRAKUST 4364/PT/100 W tenway switches

- personal computer

The four-wires method for measuring temperatures eliminates the effect of thermal changes on the resistances in the cable line. Automatic regulation of the measurement and recording of the measured values in real time is controlled by connecting of measurement sets with a PC.

All the technical advantages of the ULTRAKUST measurement sets could be used thanks to the development of a special interface. The controlling PC program is able to set the series of switches to the beginning state, to switch the measurement place to the real time dependence, to calculate averages from several values in one measured place, to correct the measured values according to a calibration constant, to draw the time-dependent temperature distribution on the screen monitor, and finally to record the results for future calculations.

The special PC program was suitable for this type of measurement requiring long-time recording of slowly changing data in many different locations. The speed of measurement was limited by speed of the ULTRAKUST measurement sets.

\section{Model of climate temperature loading}

The temperature of the external environment changes in connection with the daily and annual cycles. The value of the external temperature is determinated by the temperature of the ambient air, solar radiation, and the speed of the air flowing around the bridge structure. These most important factors are combined into the equivalent sun-temperature $T_{\text {as }}$ expressed in equation (1)

$$
T_{\mathrm{as}}=T_{\mathrm{a}}+\frac{1}{\alpha}\left(I_{\mathrm{g}} p\right)
$$

where $T_{\mathrm{a}}=T_{\mathrm{a}}(t)$ air temperature

$$
\begin{array}{ll}
I_{\mathrm{g}}=I_{\mathrm{g}}(t) & \text { intensity of global solar radiation } \\
\alpha=\alpha(v) & \text { heat-transfer coefficient depending on air } \\
& \text { speed } \\
p & \text { coefficient of surface absorption } \\
t & \text { time }
\end{array}
$$

The value of $\mathrm{T}_{\mathrm{as}}$ is applied in Fourie's law by expression (2)

$$
-\left.\lambda_{\mathrm{n}} \frac{\partial T}{\partial n}\right|_{\Gamma}=-\alpha\left(T-T_{\mathrm{p}}\right)
$$

where $T=T(x, y, t) \quad$ temperature field

$\begin{array}{ll}\Gamma & \begin{array}{l}\text { surface of area where the heat-transfer } \\ \text { boundary condition is used }\end{array} \\ n & \text { vector of outside normal } \\ \lambda_{\mathrm{n}} & \text { coefficient of thermal conductivity } \\ T_{\mathrm{p}} & \text { surface temperature of structure }\end{array}$

The time dependent distribution of the external environment in summer time used for computation of an unsteady temperature field is shown in Fig. 3 and in Temperature chart No. 1, 2, 3 and 4 .

Due to the high heat capacity of the concrete bridge structure it is necessary to use the unsteady temperature field to achieve agreement between the measured and computed values.

The temperature loading state is defined as the time dependent progression of the separate temperature states that can be observed in the structure during all seasons of the year.

\section{Calculation of temperature fields}

In order to evaluate thermal stresses evaluation it is necessary to know the temperature distribution in the whole area of a cross section. For this reason the experiment is the most important criterion for the accuracy of unsteady temperature

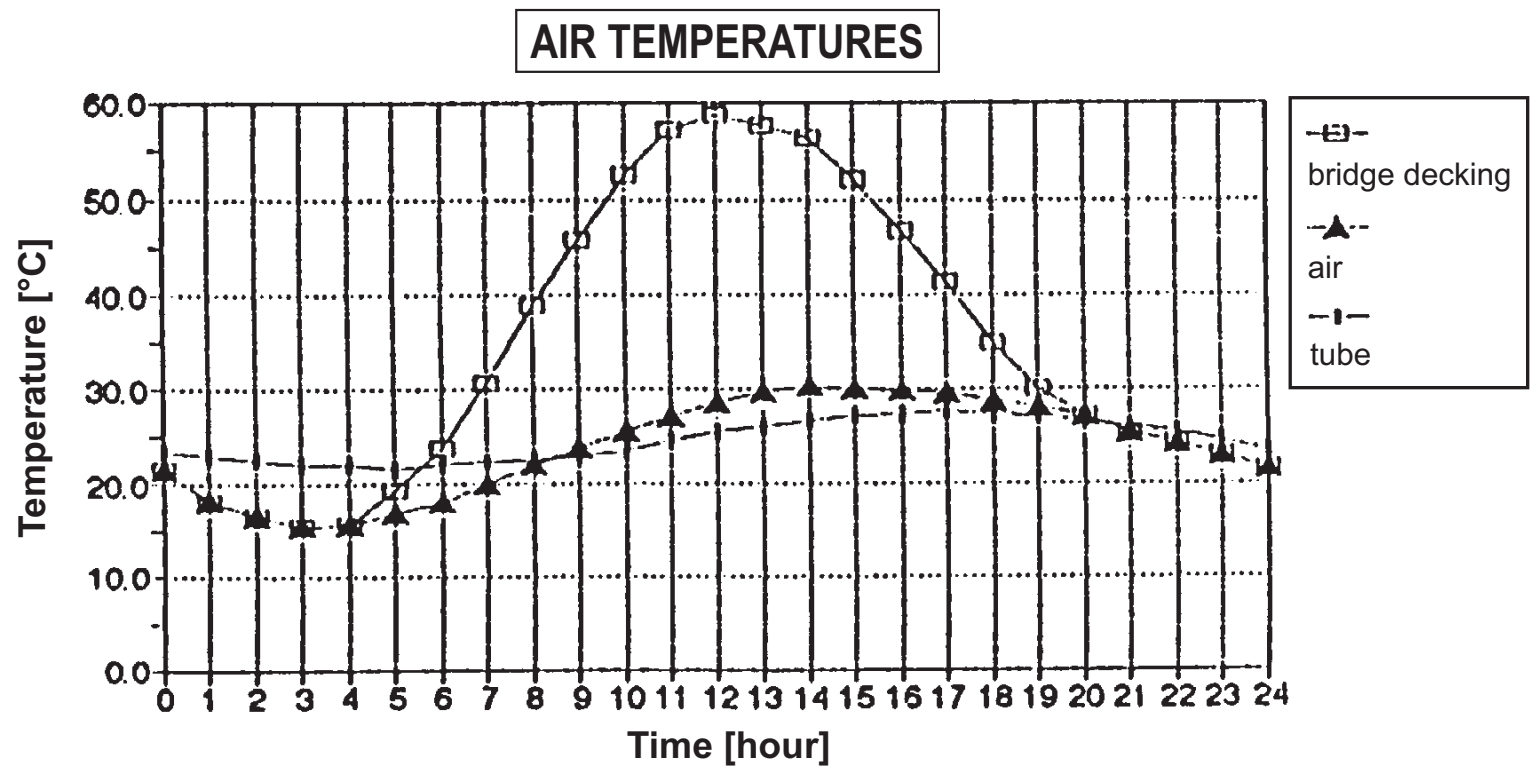

Fig. 3: Time dependent distribution of environment temperature in summer 


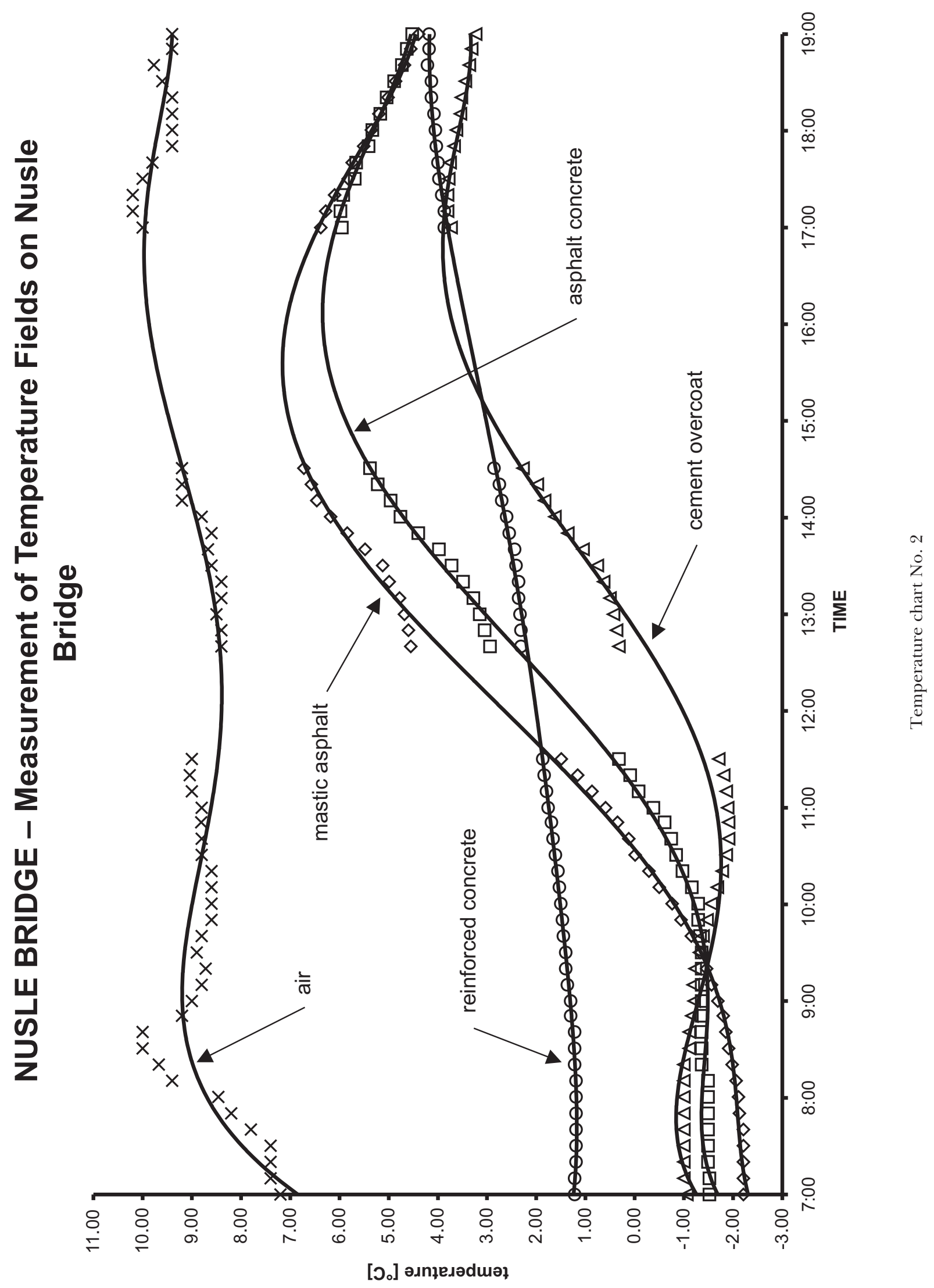



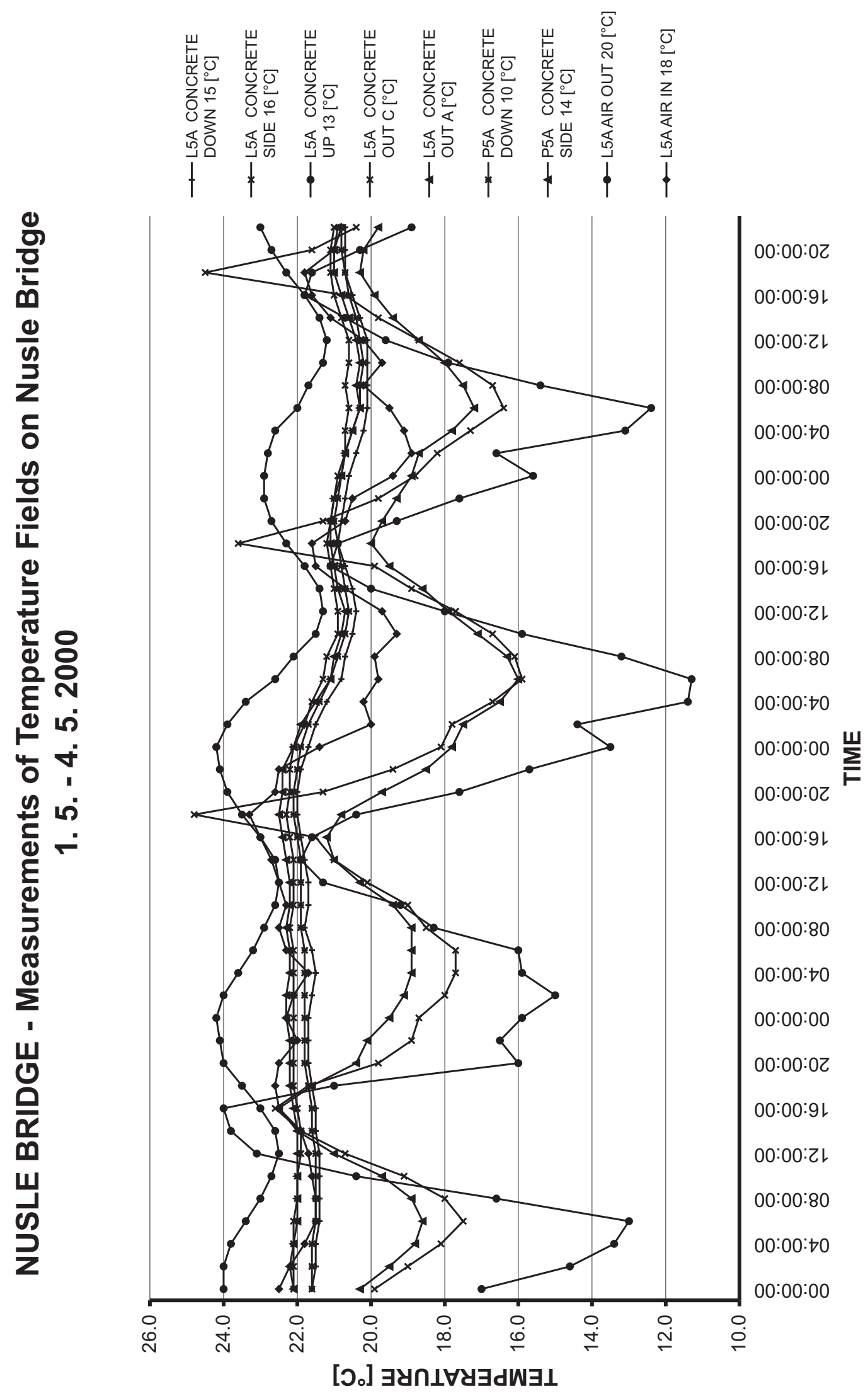


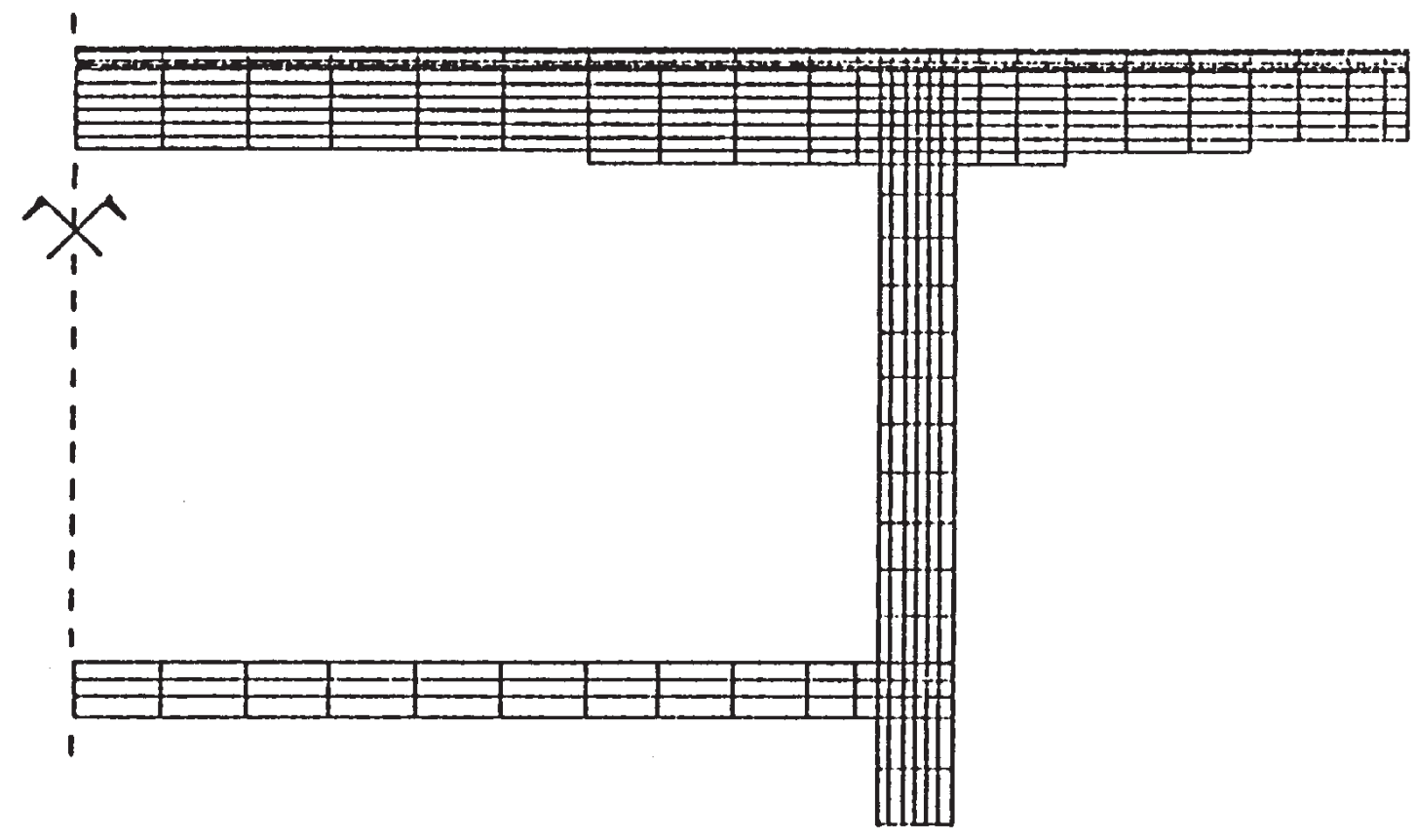

Fig. 4: Discretisation of the cross section into the finite elements

Table 2: Thermotechnical properties of materials

\begin{tabular}{|c|l|c|c|c|}
\hline NUMBER & \multicolumn{1}{|c|}{ MATERIAL } & $\begin{array}{c}\lambda \\
{[\mathrm{W} / \mathrm{mK}]}\end{array}$ & $\begin{array}{c}\mathrm{c} \\
{[\mathrm{J} / \mathrm{kgK}]}\end{array}$ & $\begin{array}{c}\rho \\
{\left[\mathrm{kg} / \mathrm{m}^{3}\right]}\end{array}$ \\
\hline 1 & mastic asphalt & 1.55 & 650 & 2400 \\
\hline 2 & asphalt-concrete & 1.40 & 650 & 2400 \\
\hline 3 & cement overcoat & 1.00 & 900 & 2200 \\
\hline 4 & hydroinsulation & 0.70 & 900 & 2200 \\
\hline 5 & prestressed concrete & 1.71 & 960 & 2500 \\
\hline
\end{tabular}

field computation. The distribution of the temperature field in the structures is described by Fourier's law for two dimensional solution by the following equation

$$
\frac{\partial}{\partial x}\left(\lambda_{\mathrm{x}} \frac{\partial T}{\partial x}\right)+\frac{\partial}{\partial y}\left(\lambda_{\mathrm{y}} \frac{\partial T}{\partial y}\right)=\rho c \frac{\partial T}{\partial t}
$$

where $\lambda_{\mathrm{x}}, \lambda_{\mathrm{y}}$ coefficient of thermal conductivity

$$
\begin{array}{ll}
\rho & \text { density } \\
c & \text { heat capacity }
\end{array}
$$

The heat transfer between the environment and the surface of the structure is described in boundary condition (2).

It is neccessary to know the initial condition in time $\mathrm{T}=\mathrm{T}_{0}$ to start the solution of equation (3). In accordance to with cyclic character of the boundary condition we determine the initial condition from the steady temperature state. After finishing 1 or 2 one-day cycles of computations, the influence of any inaccurate choice of initial condition totally disappears.
Equation (3) is solved by the finite element method. This process is advantageous, because the discretisation of the cross section into finite elements (Fig. 4) also remains for the computation of thermal deformations and stresses. The time integration passes by the incremental method by means of the Cranck-Nicholson scheme.

The thermotechnical properties of each material used in the bridge structure are described in Tab. 2.

\section{Evaluation of computations and comparison with experiment}

The agreement between measured and evaluated temperature distributions at each measured point is the criterion for the truthfulness at the model of the environment and for the suseement computation. Fig. 5a, b show the distribution of isothermal lines in the cross section at two moments in the 24-hour cycle. 
The first aim of this paper is to compare the experimentally measured and computed time dependent temperature distributions, see Fig. 6a, b, c (temperatures in the bridge decking) and Fig. 7 (temperatures in the bridge structure).

We can see from the Fig. 6, 7 that the differences between the computation and the experiment are negligible for our purposes. The sources of the deviations are as follows:

- the heat-transfer coefficient is time mutable
- the intensity of the solar radiation is locally suppressed due to cloud movements

- the real shape of the cross section differs slightly from our theoretical model.

This means that the evaluated temperature field can be used as an objective basis for computing the thermoelastic stresses.

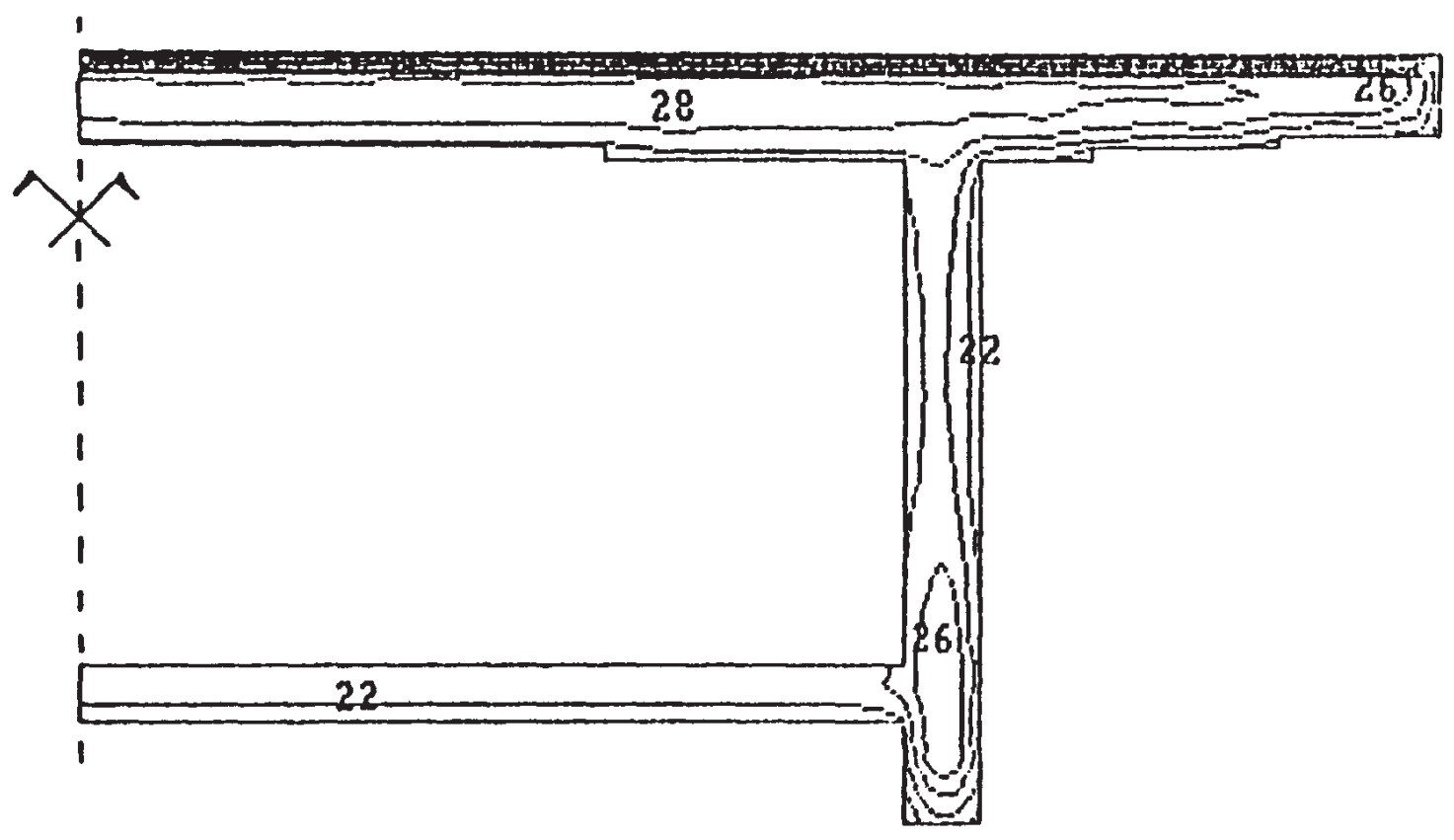

a)

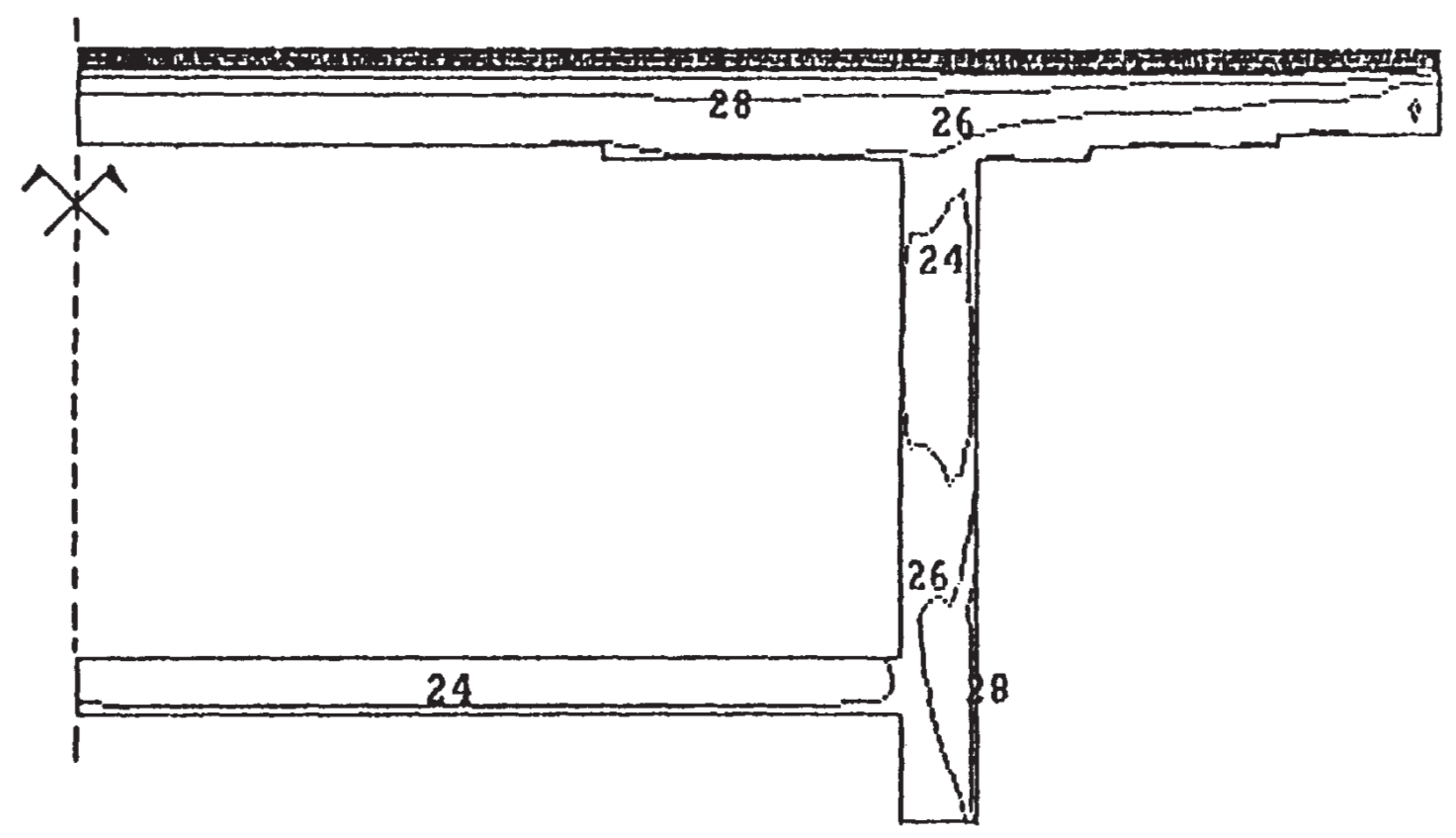

b)

Fig. 5: Isothermal lines: a) 6 a. m., b) 12 a. m. 


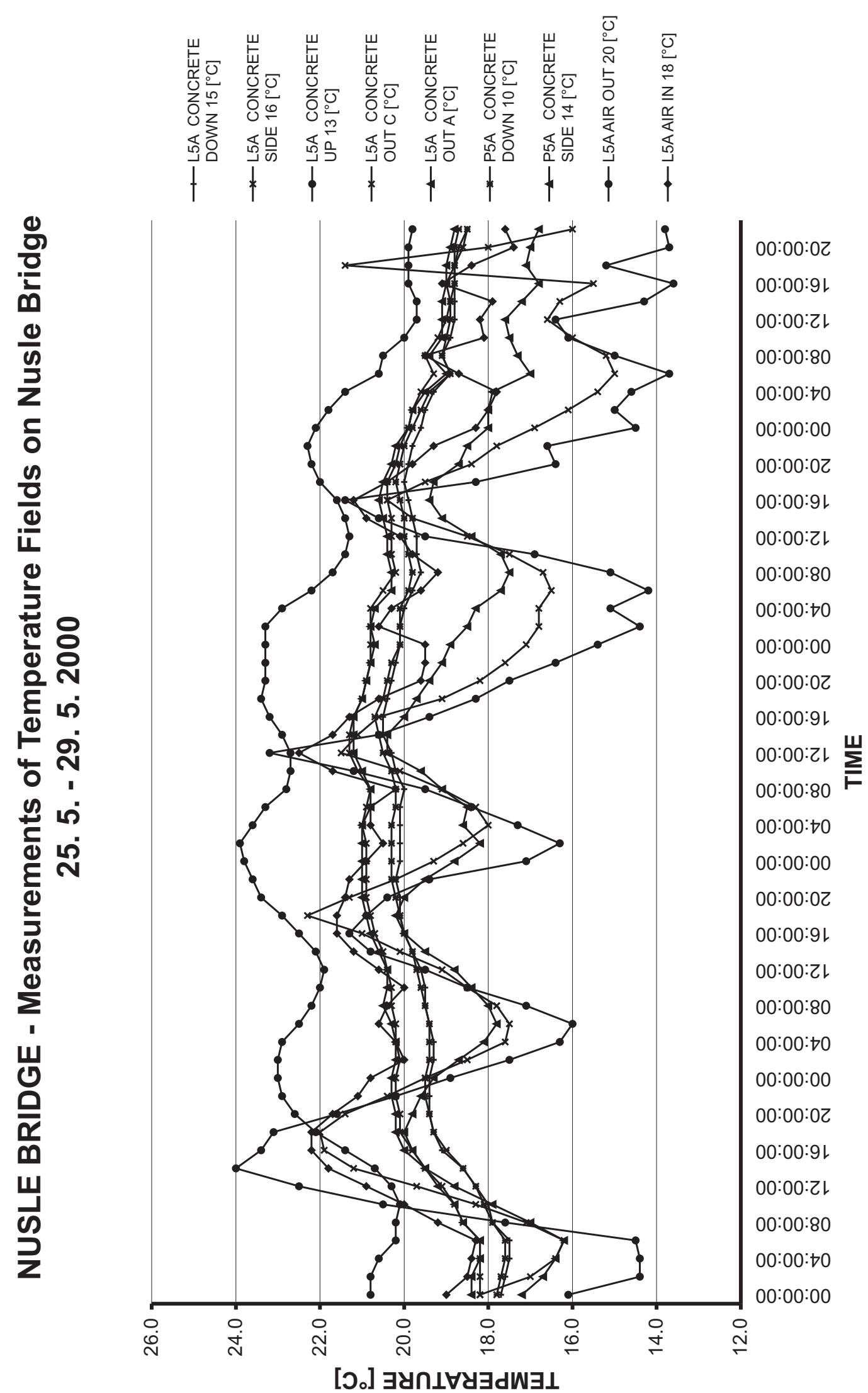




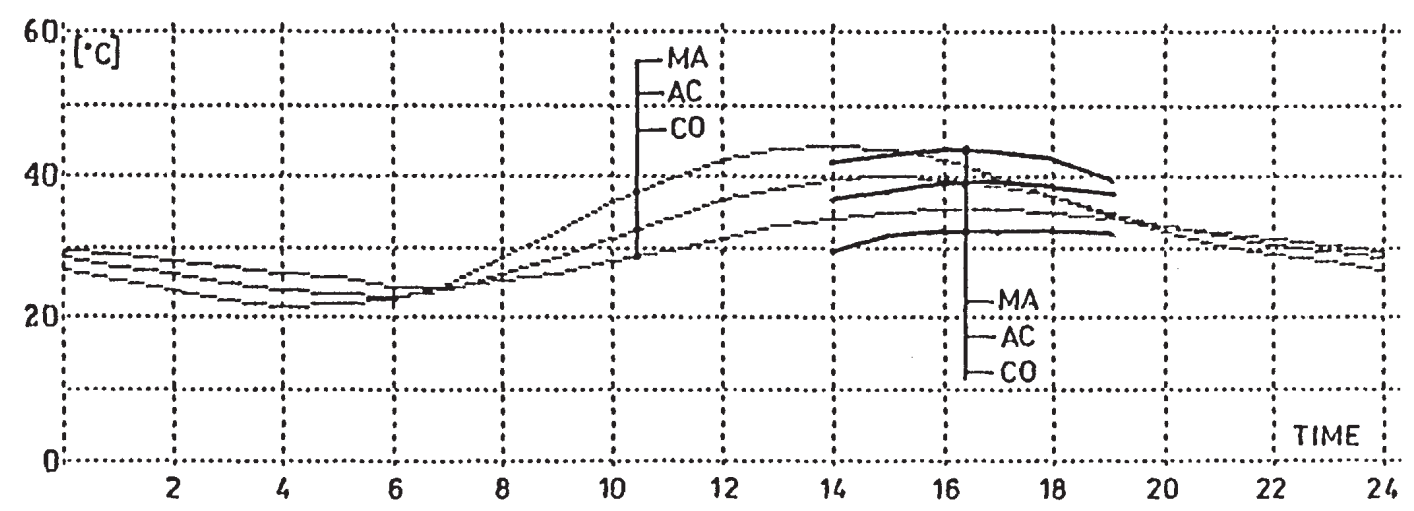

a)

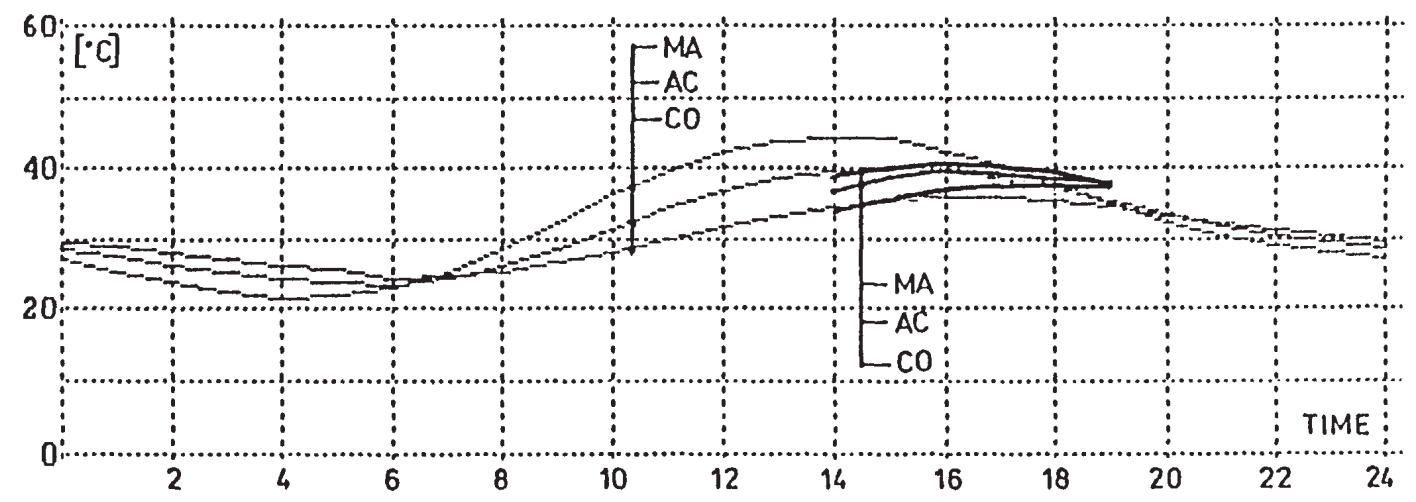

b)

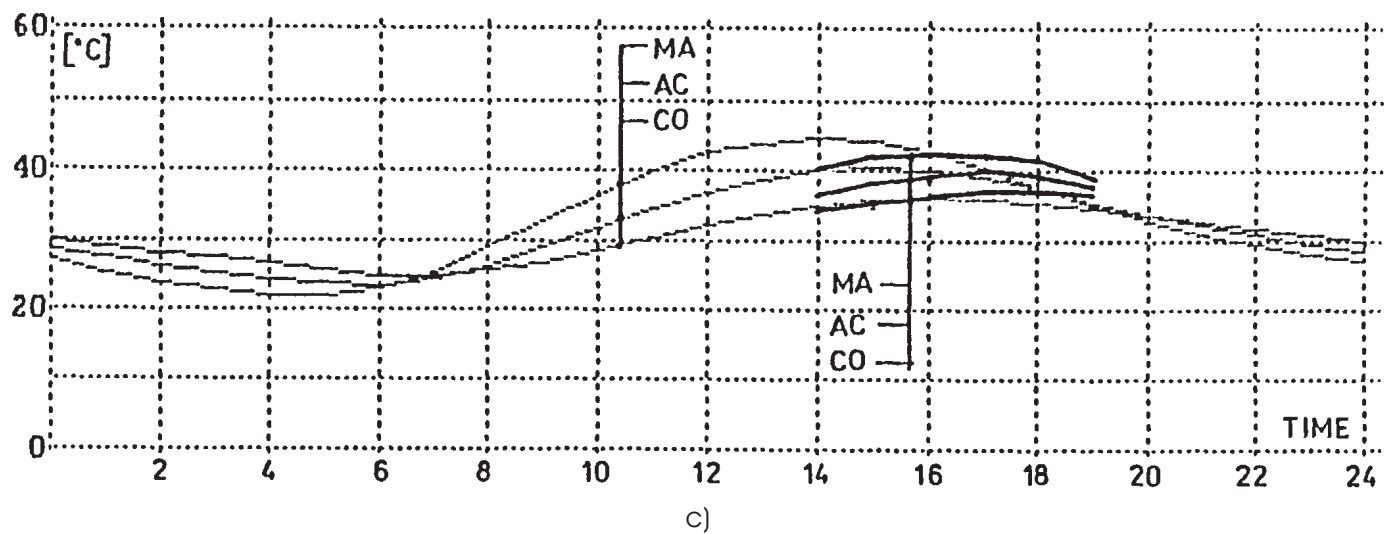

Fig. 6: Comparison of measured and computed temperatures: a) Outside traffic line, b) Middle traffic line, c) Inside traffic line

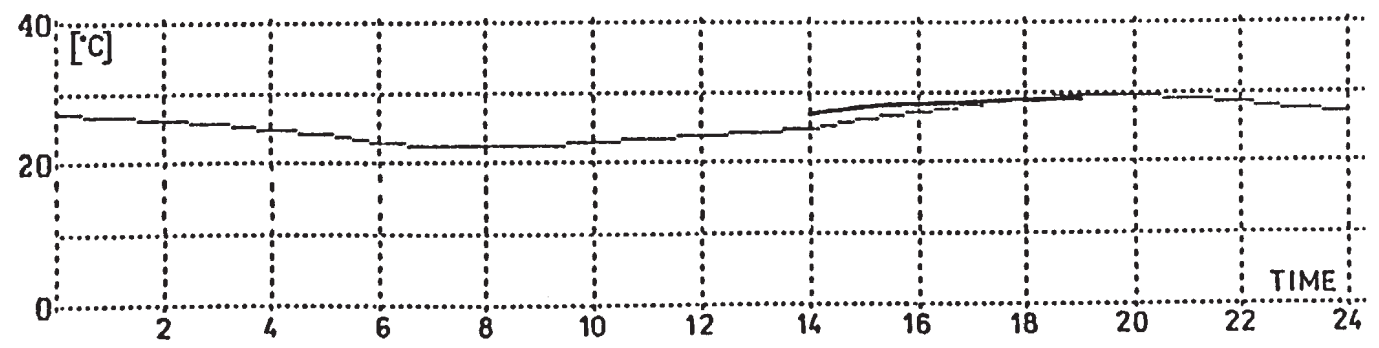

Fig. 7 Comparison of measured and computed temperatures in the bridge structure 


\section{Evaluation of Stress Fields}

The second aim of this paper is to evaluate the stress fields. The two-dimensional fields of deformations and stresses are computed in the same perpendicular network of finite elements as the temperature fields. The bridge structure is loaded by the volume changes caused by the previous temperature states. The physical properties of the materials used for the computation are shown in Tab. 3. It should be mentioned that a value of $10{ }^{\circ} \mathrm{C}$ was chosen for the assembling temperature.
The following figures $(8 \mathrm{a}, \mathrm{b})$ demonstrate the important factor influencing the durability and reliability of structures. The cyclic temperature changes involve the corresponding response in the thermal stresses. It is evident that the compressive stresses change into tensile stresses and vice versa in one 24-hour cycle. In Fig. 8a, b this fact is noticeable, especially on the outside surface of the vertical wall, where the values of the tensile stresses are in the range from 0.46 MPa to $0.80 \mathrm{MPa}$ at 6 a.m., while at 12 a.m. we observe compressive stresses in range from $0.3 \mathrm{MPa}$ to $0.60 \mathrm{MPa}$ in the same place.

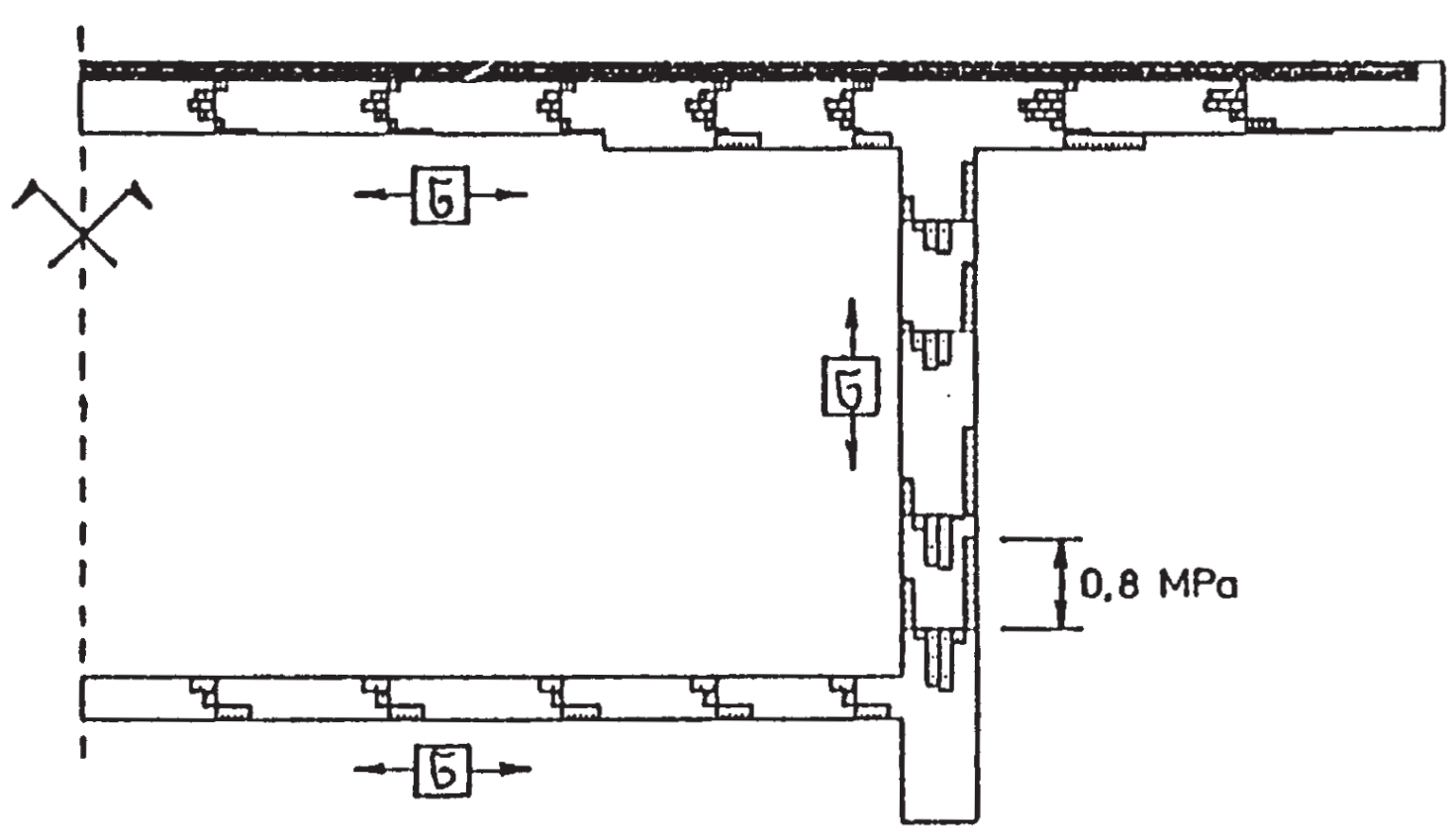

a)

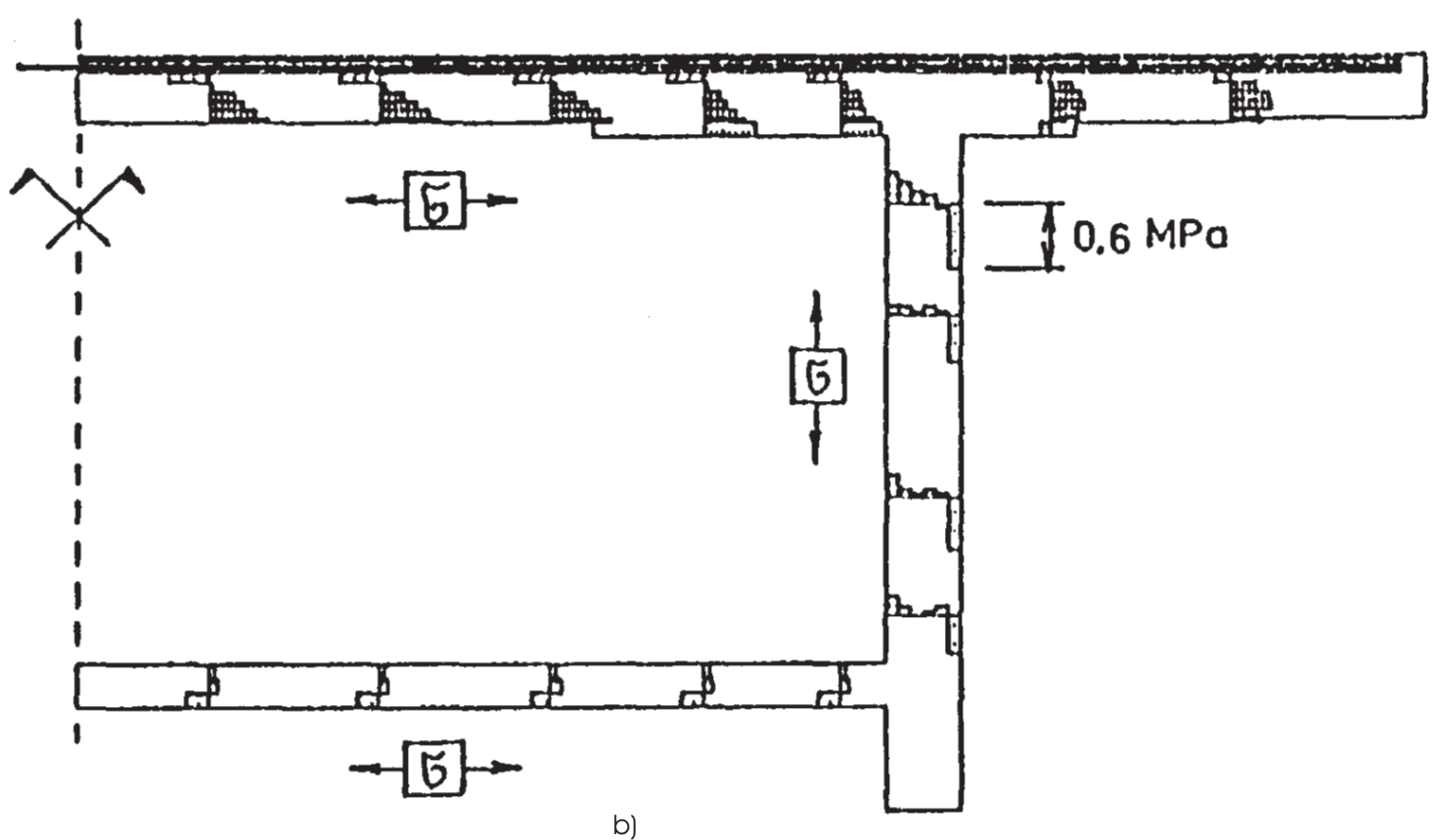

Fig. 8 Longitudial axial stresses in the cross section: a) 6 a.m., b) 12 a.m. 
Table 3: Physical properties of materials

\begin{tabular}{|c|c|c|c|c|}
\hline NUMBER & MATERIAL & $\begin{array}{c}E \\
{[\mathrm{MPa}]}\end{array}$ & $\begin{array}{c}n \\
{[-]}\end{array}$ & $\begin{array}{c}\alpha_{\mathrm{t}} \\
{[1 / \mathrm{K}]}\end{array}$ \\
\hline 1 & mastic asphalt & 200 & 0.30 & 0.000050 \\
\hline 2 & asphalt-concrete & 500 & 0.15 & 0.000020 \\
\hline 3 & cement overcoat & 20000 & 0.15 & 0.000012 \\
\hline 4 & hydroinsulation & 70 & 0.30 & 0.000050 \\
\hline 5 & prestressed concrete & 36000 & 0.15 & 0.000010 \\
\hline
\end{tabular}

The absolute peaks of the stresses that are reached may not be in the same level of the material strength, but due to the cyclic character of the loading (daily and annually) the fatigue strength can be exceeded in this place, and so become a potential cause of structural failure.

\section{Acknowledgement}

This project is being carried out with the participation of undergraduate students Jan Pytel, Jakub Rímal and Jana Zaoralová.

This research has been supported by the Grant Agency of the Czech Republic under grant No. 103/00/0776.

\section{References}

[1] Římal, J., Klobouček, B.: Reconstruction of Bridge Decking of Nusle Bridge. Measurement of Thermal Fields, research report, CTU, 1981

[2] Klobouček, B., Rímal, J.: Reconstruction of Bridge Decking. of Nusle Bridge. PUDIS Prague, 1980

[3] Bažant, Z. P., Kř́stek, V., Vítek, J. L.: Drying and Cracking. Effects in Box-Girder Bridge Segment. Journal of Structural Engineering, 1992

[4] Ǩímal, J.: Measurement of Temperature and Moisture Fields of the Charles Bridge in Prague. CTU, Prague, 1991
[5] Ǩímal, J.: Impact of Temperature Fields on Degradation Processes of the Bridge Deck and Bridge Structure. CTU, Prague, 1990

[6] Kímal, J.: The Measurement of Thermal Fields in the Bridge Deck and Bridge Structure of Nusle Bridge in Prague. New Requirement for Materials and Structures, Proceedings of the Conference - New Requirement for Materials and Structures, CTU, 1998

[7] Ǩímal, J., Jelínek, V., Vodák, F.: Climatic Impact of the Bridge Structure of the Charles Bridge in Prague. Conference Proceedings 1998, CTU, Faculty of Civil Engineering, 1998

[8] Vítek, J., Křístek, V., Římal, J.: Construction Sequence of Concrete Structures. Proceedings of Workshop 98, CTU, Prague, 1998, p. 951

[9] Ǩ́mal, J.: Evaluation of Temperature Fields on the Reinforced Concrete Slab and Bridge Structure of Charles Bridge. CTU Reports 2001, CTU, Prague, 2001, p. 846

Doc. RNDr. Jaroslav Římal, DrSc.

phone: +420224354702

fax: +420233333226

e-mail: rimal@fsv.cvut.cz

Czech Technical University

Faculty of Civil Engineering

Thákurova 7

166 29, Prague 6, Czech Republic 